Diagnostic

\section{Redefining disease definitions and preventing overdiagnosis: time to re-evaluate our priorities}

10.1136/bmjebm-2019-111219

Check for updates

Carl Heneghan, ${ }^{\circledR}{ }^{1}$ Kamal R Mahtani ${ }^{\odot 2}$

${ }^{1}$ Nuffield Department of Primary Care Health Sciences, University of Oxford, Oxford, UK, ${ }^{2}$ Nuffield Department of Primary Care Health Sciences, University of Oxford, Oxford, UK

Correspondence to: Professor Carl Heneghan, Primary Care Health Sciences, University of Oxford, Oxford OX2 6GG, UK; carl.heneghan@phc.ox.ac.uk

In their paper, Ray Moynihan and colleagues ${ }^{1}$ analyse the problems of disease thresholds and their impact on expanding disease definitions, overdiagnosis, overtreatment and wasted resources. The group calls for a new approach to developing disease definitions that includes being primary care led, people-centred, independent of commercial interests and informed by better guidelines.

The authors highlight several concerns with the current approach to disease definitions. For example, approximately half of the older population are defined as having chronic kidney disease, yet many are asymptomatic with no negative impact on their day-to-day living. New thresholds for gestational diabetes have meant the prevalence has doubled, without a clear indication of the outcomes that may be affected. Furthermore, new hypertension guidelines have labelled half of the adult population as hypertensive. Changing definitions place a considerable burden on patients and an overly stretched healthcare system that is required to manage these "phantom conditions'.

Primary care is likely to be most affected by this, given it is the 'front-line' setting for delivering both prevention and management while also facilitating access to the wider health system. ${ }^{1}$ New disease definitions will further add to the increase in testing required for the diagnosis and monitoring of new indications. In the UK, * GP practice annual consultation rates per person have already increased by $10.5 \%$ annually from $2007-$ 1008 to $2013-2014 ;^{2}$ tests have increased by $8.5 \%$ per year over a similar timeframe ${ }^{3}$ and the number of prescription items has increased by almost half in the decade to $2016 .{ }^{4}$ The opportunity cost of all this extra work is vast.

Identifying problems that were never going to cause harm or by medicalising everyday life experiences through expanded definitions of diseases has contributed to the concept of overdiagnosis. Along with the increasing availability of advanced diagnostic technologies, financial incentives and the general enthusiasm for screening programmes, broadening disease definitions acts to encourage overdiagnosis in primary care and may lead to overtreatment, disease labelling with added psychological harms and waste across the health system. ${ }^{5}$

Solutions to the problems of overdiagnosis are not straightforward. ${ }^{6}$ One solution proposed by Moynihan and colleagues is the end to the specialist dominance of disease definitions within guidelines; and instead, replace them with primary care led clinicians, along with citizen representation that is independent of commercial interests; and such an approach should be informed by new guidance from the Guidelines International Networks. ${ }^{7}$ International coordination of disease definitions and their thresholds could also help to minimise overdiagnosis.

Work on disease definitions has arisen as part of the Preventing Overdiagnosis scientific conferences and associated activities. ${ }^{8}$ Further solutions may also come from this movement. Including being discussed and debated in December of this year at the Preventing Overdiagnosis Conference (PODC) in Sydney. At PODC 2019, there will be talks, discussions and research planning meetings on how to try and systematically estimate the extent of overdiagnosis and overdetection across many conditions.

The Royal College of General Practitioners response informs us: 'This paper could be just the impetus we need to re-evaluate our priorities for some aspects of patient care.' ${ }^{9}$ For conditions where the burden of disease lies within primary care it seems sensible that guidance is developed from within this setting; thresholds for decisions and actions are informed by the balance of the benefits and the harms, and patient preferences are incorporated into guideline recommendations. The sheer number of guidelines that exist in the major areas of morbidity and mortality may, however, impede progress: a review of cardiovascular risk factors found 117 published guidelines, of which 90 were published by national or international bodies. Global primary care organisations coordination disease definitions, and their associated thresholds, could be a more useful approach for influencing global guidelines and minimising the harms of overdiagnosis. Above all, though, there is a need to enhance the evidence base for overdiagnosis and its consequences. For many disease areas (cancer aside), there is very little research evidence to quantify the extent of overdiagnosis and its associated problems.

Contributors $\mathrm{CH}$ wrote the first draft and $\mathrm{KM}$ contributed subsequent drafts.

Competing interests $\mathrm{CH}$ and KRM are supported by the NIHR School for Primary Care Research Evidence Synthesis Working group (NIHR SPCR ESWG project 390). CH is Director of CEBM and also supported by the NIHR Oxford Biomedical Research Centre, is an NIHR Senior Investigator and Editor-in-Chief of BMJ Evidence-Based Medicine. KRM is an Associate Editor of BMJ EBM. CEBM jointly runs the EvidenceLive Conference with the BMJ and the Preventing Overdiagnosis Conference with international partners based on a non-profit making model.

Patient consent for publication Not required.

Provenance and peer review Commissioned; internally peer reviewed.

๑ Author(s) (or their employer(s)) 2019. No commercial re-use. See rights and permissions. Published by BMJ.

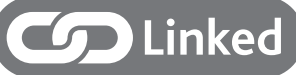

http://dx.doi.org/10.1136/bmjebm-2018-111148 
To cite: Heneghan C, Mahtani KR. BMJ Evidence-Based Medicine 2019;24:163-164.

\section{References}

1 Gulliford M. Access to primary care and public health. Lancet Public Health 2017;2:e532-3.

2 Hobbs FDR, Bankhead C, Mukhtar T, et al. Clinical workload in UK primary care: a retrospective analysis of 100 million consultations in England, 200714. Lancet 2016;387:2323-30.

3 Anon. Temporal trends in use of tests in UK primary care, 2000-15: retrospective analysis of 250 million tests. BMJ 2019;364:1444.

4 The King's Fund. The rising cost of medicines to the NHS. https://www. kingsfund.org.uk/sites/default/files/2018-04/Rising-cost-of-medicines.pdf (accessed 16 Apr 2019).
5 Kale MS, Korenstein D. Overdiagnosis in primary care: framing the problem and finding solutions. BMJ 2018;362:k2820.

6 Brodersen J, Schwartz LM, Heneghan C, et al. Overdiagnosis: what it is and what it isn't. BMJ Evid Based Med 2018;23:1-3.

7 Moynihan R, Brodersen J, Heath I, et al. Reforming disease definitions: a new primary care led, people-centred approach. BMJ Evid Based Med 2019;24:170-3.

8. Preventing over diagnosis. About Us. https://www.preventingoverdi agnosis.net/?page_id=6 (accessed 15 Apr 2019).

9. Royal College of General Practitioners. Widespread debate needed on 'disease mongering' and overdiagnosis of patients, says RCGP in response to BMJ Evidence-Based Medicine paper on definitions of disease. https:// www.rcgp.org.uk/about-us/news/2019/april/widespread-debate-needed-ondisease-mongering-and-overdiagnosis-of-patients-says-rcgp.aspx (accessed 16 Apr 2019). 